\title{
VISÕES DO EXOTISMO NA ROMA BARROCA: A FONTE DOS QUATRO RIOS E O OBELISCO DA PRAÇA NAVONA
}

Evelyne Azevedo ${ }^{1}$

\section{Resumo}

Esta comunicação tratará das representações do exótico no monumento de Bernini, a Fonte dos quatro rios e o obelisco que a encima, situado na Praça Navona em Roma. Centrando-nos nos elementos iconográficos vinculados ao exotismo de matiz tanto egípcio como americano e articulando simultaneamente a idéia de dominação reivindicada por Roma através de seu passado imperial e sua afirmação presente através da representação do mundo ultramarino conquistado pelo Cristianismo.

Palavras-chave: Fonte; Bernini; Barroco; Kircher; Exotismo

\begin{abstract}
This paper examines different representations of the exotism in Bernini's Four Rivers Fountain and the obelisk that raises upon it, located at Navona's Place, in Rome. It concentrates upon the study of iconographic elements linked both to the Egyptian and American elements exotism as well as with Roman propaganda of its imperial past renewed trough its dominion of the overseas wold.
\end{abstract}

Key Words: Fountain; Bernini; Baroque; Kircher; Exotism

Nesta comunicação discutiremos aspectos da representação do exotismo na Roma barroca centrando-nos nos elementos iconográficos da fonte dos quatro rios de Gian Lorenzo Bernini vinculados tanto ao Egito Faraônico quanto ao Novo Mundo. Esses elementos articulam-se com a noção de dominação reivindicada por Roma através de seu passado imperial e sua afirmação presente através da representação do mundo ultramarino pelo Cristianismo.

A chamada Fonte dos Quatro Rios, projetada pelo arquiteto, pintor e escultor Gian Lorenzo Bernini (1598-1680), situa-se na Praça Navona, em Roma, tendo sido construída entre 1648 e 1651. Bernini vinculou-se cedo ao Papa Urbano VIII, cujo patronato marcou decisivamente a carreira do artista. Já no primeiro ano de seu pontificado, o artista foi nomeado supervisor das fundições no Castelo Sant'Angelo e superintendente do aqueduto Acqua Felice. Em 1624, foi indicado supervisor do Acqua Vergine, cuja construção remonta aos tempos do Império e cuja sobrevivência perpassa a Idade Média, sendo o único a não ser desativado neste período. No ano de 1625, passou ao cargo de supervisor das fontes da Praça Navona, em que trabalharia posteriormente. Sucedeu o pai como principal arquiteto do Acqua Vergine, após a sua morte, em 1629. ${ }^{2}$

\footnotetext{
${ }^{1}$ Orientadora: profa. Maria Cristina Louro Berbara, Artes - História da Arte, Universidade Estadual do Rio de Janeiro

2 MARDER, T. A. "Bernini and the art of architecture”, Nova Iorque: Abbeville Press, 1998, p. 20.
} 
Desde a Antiguidade os aquedutos tiveram grande importância na distribuição de água na antiga Roma, permitindo sua expansão durante o Renascimento. $O$ aumento no fornecimento de água permitiu que a população ocupasse as áreas periféricas da cidade. Por essa razão, as políticas papais priorizaram a reforma e o aumento do Acqua Vergine, em fins do século XVI, construindo novas fontes ao longo do seu caminho. No fim da primeira metade do século XVII, a família Pamphili decidiu patrocinar a construção de uma fonte para celebrar sua presença na Praça Navona (em função das obras no palácio da família em 1644). ${ }^{3}$ A fonte marcaria um novo ponto de fornecimento de água bem no centro da praça, entre duas outras fontes situadas às suas margens. O local, construído em 86 d.C. serviu originalmente como estádio de corrida sob o Imperador Domiciano e suas fundações foram utilizadas na construção de prédios mais modernos o que permitiu que o grande espaço aberto permanecesse inalterado.

Com o fim da Guerra dos Trinta Anos, em 1648, na qual os jesuítas tiveram importante papel, era necessário reafirmar o poder papal e a amplitude do catolicismo no mundo. A Igreja católica pretendia estender seus domínios até o Extremo Oriente e para isso precisaria se utilizar de uma linguagem universal capaz de ser amplamente compreendida. Por trás desse objetivo havia dois interesses por dois orientes distintos: o interesse econômico e religioso pelo Extremo Oriente, que conduziu o estudo das culturas chinesa e japonesa, e o cultural e científico pelo antigo Próximo Oriente, que levou à pesquisa das antigas religiões politeístas.

É em meio a esse contexto que o Papa Inocêncio X encomenda sua fonte, que deveria simbolizar os quatro rios da Terra e sobre a qual deveria haver um obelisco egípcio, primeiro a Borromini e depois a Bernini, com o claro interesse de representar a soberania católica sobre o paganismo e o mundo.

Athanasius Kircher, jesuíta alemão, foi escalado durante o papado de Urbano VIII para chefiar uma comissão de interpretação dos hieróglifos e posteriormente, trabalhou para a família Pamphili. ${ }^{4}$ Kircher está situado na ponta da tradição humanista. Um dos últimos colecionistas, o jesuíta era um estudioso não só do mundo antigo, mas também do Oriente moderno. Um homem que procurava deter um saber global e que lhe conferia uma posição idônea para atuar no interior da cultura oficial com ampla disponibilidade de recursos econômicos para financiar suas pesquisas e suas publicações. ${ }^{5}$

Desta forma é que os estudos do padre Kircher eram incentivados, pois revelariam cientificamente a prova de que o cristianismo já havia sido revelado aos antigos egípcios. Desvendar a sua linguagem seria alcançar seu conhecimento. Kircher considerava que o Egito era o epicentro da humanidade, assim como Grécia e Roma seriam emanações da cultura hermética egípcia e do Irã Zoroástrico.

Acredita-se que Kircher estivesse intimamente relacionado ao projeto da fonte, pois anunciou a publicação de seu texto Obeliscus Pamphilius junto com a transferência do obelisco, que seria restaurado e utilizado por Bernini, do Circo Massimo (onde se situava) para a Praça Navona. Neste texto, o jesuíta fornece um método de tradução dos hieróglifos, com as

\footnotetext{
3 Id., Ibid., p. 95.

${ }^{4}$ FINDLEN, Paula (ed.). Athanasius Kircher: the last man who knew everything. Nova Iorque: Routledge, 2004, p. 53.

${ }_{5}^{5}$ RIVOSECCHI, Valerio. Esotismo in Roma Barocca: studi sul padre Kircher.Roma: Bulzoni Editore, 1982, p. 53.
} 
inscrições do referido obelisco, além de um tratado sobre a sabedoria egípcia e seu valor filosófico e histórico. ${ }^{6}$

A interpretação dos elementos que compõem a fonte associada ao pensamento kircheriano serão a nossa chave de leitura do monumento proposto por Bernini. Kircher insere-se na longa caminhada de decifração dos hieróglifos, cujo objetivo era desvendar os seus mistérios e reconstruir uma linguagem nova e universalmente válida através da análise do simbolismo antigo. Estes estudiosos em meio aos quais Kircher se situa, acreditavam que os hieróglifos constituíam mais que uma linguagem, eram considerados a base de uma escritura sagrada, arquetípica e, por isso, universal. Sua tradução permitiria assim o acesso a uma enorme gama de conhecimento: coisas do passado, presente e futuro.

De acordo com o Neoplatonismo, a sabedoria egípcia era a fonte de desenvolvimento do pensamento. Os hieróglifos, imitando a natureza, eram uma manifestação simbólica da razão invisível, uma vez que os animais, as plantas e os outros elementos naturais são a maneira como Deus se expressa. Ao escrevê-los, o sacerdote estaria apenas copiando aquilo que já estava escrito no grande livro da natureza. Eram assim expressões da verdade divina. Decifrálos era desvendar os mistérios herméticos escondidos em seus símbolos, revelados apenas aos iniciados. Kircher pretendia demonstrar o caráter de pré-figuração dos Cristianismo, religião revelada. Provando desta forma que os próprios egípcios já eram monoteístas e que seus mitos cosmogônicos eram, na verdade, fábulas de função arquetípica. ${ }^{7}$

As traduções das inscrições hieroglíficas tornaram-se, na realidade, projeções alegóricas da teoria filosófica da cultura neoplatônica. Traduzidos de modo arbitrário e não através de uma regra sintática, as inscrições acabaram por exprimir aquilo que melhor conviesse ao intérprete. ${ }^{8}$ Data dessa época a Hipótese Egípcia, que se tratava da idéia humanista da unidade humana e que procurava demonstrar que era possível retornar à unidade original do pensamento humano: da religião, à mitologia e à linguagem. ${ }^{9} \mathrm{Na}$ prática, os hieróglifos perderam seu valor místico para obter valor teológico, próprio do simbolismo católico, representando a fonte de todo o conhecimento.

Além disso, Kircher acreditava também que todos os mistérios tinham caráter matemático, de modo que tudo podia ser reconduzido às formas numérica e geométrica. Sistema esse considerado idôneo para representar a essência divina do universo, obscuramente intuída pelos antigos e revelada ao Cristianismo. ${ }^{10}$ No momento em que a Igreja falava na necessidade de uma comunicação universal, tentou-se reconstruir uma língua originária da humanidade, um código universal capaz de ser amplamente compreendido. Razão pela qual a pirâmide e o obelisco apresentavam implicações teológicas.

Nesse contexto, a pirâmide representava o poder divino, de onde todas as coisas provinham. A base da pirâmide representava tudo que é criado através do poder divino, cada um dos quatro vértices da base representava um elemento: ar, fogo, terra e água, todos

\footnotetext{
${ }^{6}$ Id., Ibid., p. 57.

${ }^{7}$ Id., Ibid., pp. 60 - 61.

${ }^{8}$ Id., Ibid., p. 51.

${ }^{9}$ Id., Ibid., p. 26.

10 Id., Ibid., p. 63.
} 
provenientes do ápice da pirâmide, que por sua vez representava Deus. ${ }^{11} \mathrm{O}$ obelisco, cuja forma é composta de uma pirâmide mais o tronco de uma pirâmide, representaria então a ligação entre o intelecto divino, o mundo angelical e a esfera dos elementos. ${ }^{12}$ A própria forma do triângulo constituía uma representação importante, pois simbolizava a tríade divina egípcia Osíris, Ísis e Hórus. Esse triângulo, no entanto, funcionava de maneira invertida, pois na base virada para cima encontrava-se o casal divino e na ponta virada para baixo, o filho. Ao identificar a tríade divina egípcia à Santíssima Trindade, Kircher inverte novamente o triângulo, colocando Deus no vértice principal, Jesus Cristo e o Espírito Santo na base do triângulo.

Hórus é uma divindade solar, que para os egípcios representava o sol do meio-dia. Kircher associa o Sol à figura de Deus, argumentando que o primeiro era, na realidade, um símbolo da Trindade, pois possuía três poderes distintos: o de fecundar, imperceptível, que alude ao Padre; a luz que remete ao Filho e o calor que representa o amor do Espírito Santo. Com isso, Kircher alcança dois propósitos: estabelecer uma linguagem com valores universais, de comunicação imediata conservando contudo, seu valor enigmático; ao mesmo tempo em que ele estabelece uma relação entre o paganismo e o cristianismo, reduzindo o culto politeísta a um culto solar e portanto, monoteísta.

Essa referência constante a um Egito mítico e idealizado se dava pela necessidade de reconstruir a imagem de uma sabedoria originária, que servisse de ponto de referência para explicar a nova realidade do mundo oriental. A importância da obra de Kircher não está no entanto, em seu valor histórico mas na construção de sua argumentação que, nas palavras de Rivosecchi, era "falsa mas aparentemente bem funcional e ilusória mas ao mesmo tempo real porque assim acreditava que fosse, que hoje falamos que a obra de Kircher é uma das matrizes e um dos pontos de referência do imaginário barroco" $" 13$.

Freqüentemente considerado como a máxima expressão da fonte barroca romana, o monumento berniniano propõe a compenetração entre água e rocha; elementos escultóreos e arquitetônicos; figuras mitológicas, alegóricas e cristãs. Em cada canto da base pétrea situam-se figuras colossais representando os quatro maiores rios da Terra (símbolos, por sua vez, dos quatro continentes então conhecidos): Ganges/Ásia, Danúbio/Europa, Nilo/África e Rio da Prata/América. A cada figura vinculam-se elementos simbólicos alusivos à sua respectiva zona geográfica, como por exemplo o tatu - um dos principais emblemas Setecentistas da América junto ao Rio da Prata. Todo o conjunto é encimado por um obelisco egípcio - o Obelisco Agonale, construído à época do Imperador Domiciano, imitando os modelos egípcios e copiando os hieróglifos - sobre o qual descansa não a tradicional cruz, mas uma pomba levando no bico um ramo de oliveira.

Acreditamos que essa interpretação que associa os animais da fonte à cada um dos "rios" é apenas uma das possíveis interpretações e sentidos a que o monumento se propõe. Inserido na tradição humanista como estava, nada mais natural que propusesse aos seus observadores múltiplas formas de olhar. Tendo em mente o pensamento kircheriano, podemos sugerir que a pomba sobre o obelisco representa não só o Papa Inocêncio X, como o próprio poder divino, que cabe ao papa representar.

${ }^{11}$ CIPRIANI, Giovanni. Gli obelischi egizi: politica e cultura nella Roma Barocca. Florença: Leo S. Olschki Editore, 1993. pp. $124-125$.

12 RIVOSECCHI. Op. cit., p. 64.

13 Id., Ibid., pp. $54-55$. 
Como foi visto anteriormente, esse poder emana do ápice da pirâmide e chega à base elemental através do corpo do obelisco, que representa o mundo angelical. Essa base elemental, sobre a qual Deus criou o mundo e ratificada pela representação dos quatro continentes, todos banhados pelo poder divino e, consequentemente, abarcados pela Igreja Católica.

Essa, no entanto, é a implicação "presente" do monumento. Como afirmamos anteriormente, o desvendamento do emblema significava conhecer os mistérios do passado, do presente e do futuro. Durante o Império Romano, os obeliscos egípcios eram trazidos em meio a longas caravanas que passavam pelo centro de Roma a fim de exibir espetacularmente o espólio de guerra. Tirados de antigos templos egípcios, os obeliscos exerciam a função de troféus, símbolos da vitória de Roma sobre o poder faraônico, que submeteu a grande civilização egípcia à condição de província do Império. Outros obeliscos, no entanto, foram construídos pelos próprios imperadores romanos, como no caso do Obelisco Agonale, para serem colocados nos templos dedicados ao culto dos deuses egípcios em Roma. ${ }^{14}$

Símbolos de uma era gloriosa e passada, os obeliscos eram entendidos, desde Sixtus V, como símbolos do triunfo do Cristianismo sobre o Paganismo - interpretação essa que vai de encontro com a representação dos quatro continentes do monumento berniniano, uma vez que este reflete a dominação do homem sobre a Terra e, consequentemente, a dominação cristã sobre as outras religiões.

Entretanto, de acordo com Rivosecchi, é necessário ainda estabelecer mais um significado, a que ele vai chamar "negativo" em oposição ao "positivo", que entende o monumento como símbolo de purificação. Utilizando para isso o binômio luz - sombra. Considerando então que o obelisco estaria representando o Sol e portanto, a luz; a gruta representaria a sombra. Contudo, a estes elementos devem ser acrescentados os simbolismos dos animais escolhidos para a fonte, que além de possuirem um significado complementar ao dos rios, fazem referência à mitologia egípcia. O leão simboliza a força solar, além disso, a cheia do Nilo ocorria quando o Sol atingia o signo de Leão (entre os meses julho e agosto), trazendo fecundidade ao vale do Nilo.

Em oposição à divindade solar, que Kircher atribuía a Osíris (e não a Hórus), está Seth, o "vento árido do deserto", deus do deserto e do caos. O animal que se associou a ele é o hipopótamo, também conhecido como "cavalo do rio". Bernini coloca na posição diametralmente oposta a do Leão, um cavalo com a crina agitada pelo vento e emergindo da água. Ambos representando assim o dualismo morte - regeneração, que Kircher acreditava estar presente em todas as religiões antigas. ${ }^{15}$

Desta forma é que Kircher pretendia demostrar a sua teoria humanística de uma continuidade ideal entre a antiga sabedoria mágica do Egito hermético e a verdade revelada do cristianismo. O século XVII esteve assim dividido entre duas interpretações do exotismo: de um lado a reflexão erudita sobre a cultura oriental antiga e moderna e de outro o gosto pela estranheza e pela novidade.

Não se tratava apenas de uma medida reflexiva e cognitiva, mas de um processo de apropriação em que os fragmentos das antigas civilizações eram transformados em lugares de

\footnotetext{
14 WILDUNG, Dietrich. O Egipto: da pré-história aos romanos. Lisboa: Taschen, 1998, pp. 225 - 226.
}

15 RIVOSECCHI. Op. cit., p. 130. 
memória. O exotismo pode ser então interpretado como uma forma de ampliamento da memória, releitura do passado fantástico, misterioso e exótico nascido em meio à tradição ocidental. ${ }^{16}$

\section{Bibliografia:}

AVERY, Charles. Bernini: genius of the Baroque. Boston: Bulfinch, 1997.

CHOAY, Françoise. A alegoria do patrimônio. São Paulo: Editora UNESP, 2001.

CIPRIANI, Giovanni. Gli obelischi egizi: politica e cultura nella Roma Barocca. Florença: Leo S. Olschki Editore, 1993.

FINDLEN, Paula (ed.). Athanasius Kircher: the last man who knew everything. Nova Iorque: Routledge, 2004.

MARDER, Tod A. Bernini and the art of architecture. Nova Iorque: Abbeville Press, 1998.

RIVOSECCHI, Valerio. Esotismo in Roma Barocca: studi sul padre Kircher.Roma: Bulzoni Editore, 1982.

WILDUNG, Dietrich. O Egipto: da pré-história aos romanos. Lisboa: Taschen, 1998.

${ }^{16}$ Id., Ibid., p. 43. 